Rev. Int. Contam. Ambie. 35 (4) 889-904, 2019

DOI: 10.20937/RICA.2019.35.04.09

\title{
LOS ESPACIOS VERDES COMO ESTRATEGIA DE MITIGACIÓN DE LA CONTAMINACIÓN SONORA. EVALUACIÓN Y ANÁLISIS DEL PARQUE O’HIGGINS DE LA CIUDAD DE MENDOZA-ARGENTINA
}

\author{
Green spaces as mitigation strategy to control sound pollution. \\ Assesment and analysis of O'Higgins Park in Mendoza city, Argentina \\ María del Carmen ROBLES, Claudia Fernanda MARTINEZ* y César BOSCHI
}

Instituto de Ambiente, Hábitat y Energía - INAHE - CCT CONICET-Mendoza. Facultad Regional Mendoza (UTN-FRM) Universidad Tecnológica Nacional (UTN-FRM), Av. Ruiz Leal s/n Parque Gral. San Martín (5500), Mendoza, Argentina

*Autora para correspondencia: cmartinez@mendoza-conicet.gob.ar

(Recibido: octubre 2017; aceptado: noviembre 2018)

Palabras clave: barreras vegetales, ruido, vegetación urbana

\section{RESUMEN}

La contaminación sonora constituye uno de los factores que deterioran la calidad ambiental de las ciudades, su habitabilidad y la productividad de sus habitantes. Una de las estrategias viables para mitigar este tipo de contaminación son los parques urbanos. Éstos pueden considerarse como pantallas vegetales antirruido que aportan adicionalmente otros beneficios ambientales. El objetivo del trabajo es cuantificar los niveles de presión sonora y analizar las características del parque O’Higgins en la ciudad de Mendoza, Argentina, para determinar su eficiencia como barrera para atenuar el ruido y mejorar la calidad del entorno. Se miden los niveles de presión sonora en cuatro períodos del día y diferentes puntos del parque (9) mediante registros estacionales de verano e invierno, y a partir de los cuales se han calculado distintos indicadores acústicos. La vegetación existente se caracteriza mediante relevamientos in situ y mediciones dasométricas. Los primeros resultados muestran diferencias en los niveles de presión sonora entre estaciones a causa de la presencia de especies caducifolias que en invierno pierden el follaje (64-84 \%). Se observa que para un enmascaramiento efectivo del ruido, el diseño, composición y distribución de la vegetación del parque debieran ajustarse en términos de aumentar la proporción de especies perennifolias que aporten mayor volumen de vegetación y menor transmisibilidad al ruido.

Key words: green barriers, noise, urban forestry

\begin{abstract}
Noise pollution is one of the factors that deteriorate the environmental quality of cities, their habitability and productivity of their inhabitants. One of the viable strategies to mitigate this type of pollution are urban parks. These can be considered as acoustic vegetable screens that additionally provide numerous other benefits. The aim of this study is to quantify the sound levels and analyze the O'Higgins park characteristics in Mendoza city-Argentina, to determine its efficiency as a barrier to attenuate noise and improve the environmental quality. The sound levels are measured in four periods of the day and
\end{abstract}


different points of the park (9) in summer and winter, with these, acoustic indicators have been calculated. The existing vegetation is characterized in situ with dasometric measurements. The first results show differences in sound pressure levels between seasons due to the presence of deciduous species that lose their foliage in winter (64-84\%). It is noted that for an effective masking of noise, the design, composition and distribution of park vegetation should be adjusted in terms of increasing the proportion of evergreen species that provide greater vegetation volume and lower transmissibility to noise.

\section{INTRODUCCIÓN}

En zonas urbanas los niveles de ruido ambiental son cada vez mayores principalmente como consecuencia del aumento del tráfico vehicular. En el año 2002 la Unión Europea emitió una directiva sobre ruido ambiental que unificó criterios para las normativas existentes en los países miembros y requirió a los mismos localizar las zonas de contaminación acústica y reducir sus niveles mediante planificaciones a corto, mediano y largo plazo. Se calcula que alrededor del $20 \%$ de su población está expuesta a niveles inaceptables de ruido, según es indicado por el Parlamento Europeo (2017). Actualmente en Argentina el ruido ambiental constituye un problema grave y creciente que afecta diariamente a las personas que viven y trabajan en entornos urbanizados. Esta situación también se repite en la provincia de Mendoza principalmente en su ciudad capital, siendo un problema crítico con tendencia a agudizarse y que debe ser atendido.

Una estrategia positiva y eficaz para reducir los niveles sonoros en vías de alto flujo vehicular es la implementación de barreras acústicas. Estas pueden ser elementos inertes o naturales, como es el caso de las pantallas vegetales conformadas por la vegetación urbana distribuida en el arbolado en alineación de calles o los espacios verdes, plazas o parques (Brambilla et al. 2013, Baldauf 2017).

La vegetación urbana representa un recurso posible y sustentable frente a la problemática del cambio climático, favoreciendo un ambiente saludable para los habitantes de las ciudades y su productividad. La Organización Mundial de la Salud (OMS) recomienda entre $10 \mathrm{~m}^{2}$ a $15 \mathrm{~m}^{2}$ de área verde por habitante, distribuidos proporcionalmente en relación con la densidad de población. Respecto de su función como barrera natural, permite la atenuación de los ruidos producidos por la dinámica de la ciudad. Además del efecto mecánico o de bloqueo de las estructuras verdes, los sonidos naturales generados por la vegetación y la avifauna permiten enmascarar el ruido urbano, logrando hacer más tolerable la contaminación acústica. La OMS recomienda un límite de ruido en exteriores de $55 \mathrm{~dB}(\mathrm{~A})$ en el día y $40 \mathrm{~dB}(\mathrm{~A})$ en la noche. En numerosas ciudades es abundante la información sobre la temática (Accolti y Miyara 2010, Hagler et al. 2012, Dzhambov y Dimitrova 2015). Para el caso de la ciudad de Mendoza es acotada la información existente y sistematizada en cuanto al diagnóstico de ruidos y la eficacia de los elementos de control. Se cuenta con un antecedente que indica que el rango de ruido detectado en varios sectores es excesivo y supera en $30 \mathrm{~dB}(\mathrm{~A})$ los valores recomendados por la OMS (Muñoz-Vargas y Gutiérrez 2007). Por este motivo resulta importante diagnosticar la condición del ruido en áreas relevantes de la ciudad que contienen parques urbanos y abordar el análisis de la función y eficacia de dichos espacios verdes como barreras que mitigan el ruido, aprovechando no sólo su presencia en la trama urbana sino también sus servicios ecosistémicos como atenuadores de la contaminación sonora.

El objetivo del trabajo es cuantificar los niveles de presión sonora y a través de una valoración objetiva, analizar las características físicas del parque O'Higgins de la ciudad de Mendoza, Argentina como barrera vegetal para disipar ondas sonoras, disminuir la contaminación acústica y mejorar la calidad del entorno.

\section{Hipótesis}

La vegetación urbana localizada dentro de espacios verdes actúa como moderador de la contaminación acústica en la ciudad de Mendoza. La presencia del parque O'Higgins, con características de espacio verde boscoso y de desarrollo longitudinal lindante a una vía de alto tránsito vehicular, mitiga el impacto de los ruidos.

\section{Situación problema}

Se entiende por contaminación acústica al conjunto de estímulos sonoros excesivos y molestos que alteran las condiciones normales del ambiente en una determinada zona y que pueden causar daños considerables en la calidad de vida de las personas. 
Se trata de una contaminación que puede definirse, a diferencia de los restantes tipos de contaminación, como "limpia" dado que sólo existe mientras haya una fuente de ruido activa, que una vez desaparecida no deja efecto residual (Pérez-Porto 2016).

A escala urbana el ruido puede deberse al refuerzo del sonido emitido por reflexión en las paredes y en el pavimento, fenómeno que se conoce como reverberación urbana y puede aumentar el nivel sonoro en varios decibeles respecto al que se tendría en un espacio completamente abierto (Recuero-López 1999). No obstante una de las fuentes de ruido más extendidas es la del transporte automotor. De hecho, las zonas con mayor ruido ambiental son las cercanas a vías de ingreso al microcentro por las que circula el transporte público de pasajeros.

La ciudad capital de Mendoza cuenta con 115041 habitantes, posee una superficie aproximada de $54 \mathrm{~km}^{2}$ (INDEC 2010) y concentra la actividad cultural, administrativa, comercial y el transporte público de la provincia. La ciudad es el departamento central y referente del área metropolitana de Mendoza (AMM) junto a cinco departamentos más (Godoy Cruz, Guaymallén, Las Heras, Luján de Cuyo y Maipú). Al igual que ocurre en las grandes ciudades, la población está cada vez más expuesta al ruido urbano, cuyos efectos sobre la salud y las actividades socioeconómicas se consideran un problema preocupante (Francis y Barber 2013). La disminución en la calidad de vida de sus habitantes y las altas tasas de contaminación acústica, atmosférica y visual, requieren de la presencia de espacios verdes que contribuyan a mejorar el deterioro ambiental en los espacios públicos y aporten los numerosos beneficios adicionales que éstos conllevan.

Por otro lado, en la última década el parque automotor de toda la provincia de Mendoza ha crecido progresivamente en cada uno de sus departamentos, y en particular en la ciudad capital, con una estimación creciente de automotores activos o circulantes (DNRPA 2017; Fig. 1).

\section{Barreras acústicas como dispositivos reductores de ruido}

Una de las medidas factibles para lograr la mitigación efectiva de la contaminación sonora en áreas habitadas cercanas a vías muy transitadas es la implementación de pantallas acústicas en la etapa de propagación del ruido (Halim et al. 2015). Es decir, interponer entre el emisor y el receptor una barrera que controle el ruido al dificultar su transmisión. Las barreras pueden ser inertes o vegetadas -como es el caso de parques urbanos o espacios verdes-,

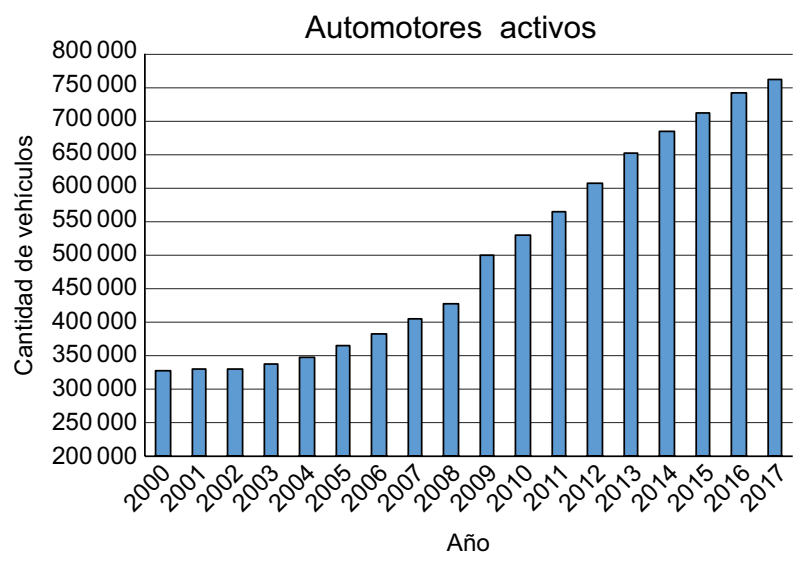

Fig. 1. Parque automotor activo en la provincia de Mendoza para el período 2000-2017. Fuente: Dirección Nacional de los Registros de la Propiedad del Automotor. Julio 2017

que aportan adicionalmente todos los beneficios de la vegetación y sus servicios ecosistémicos (Nowak et al. 2014, Tong et al. 2016).

\section{MATERIALES Y MÉTODOS}

\section{Descripción de la zona de estudio}

La ciudad de Mendoza ( $32^{\circ} 52^{\prime}$ '57' LS y $68^{\circ} 49^{\prime}$ $19^{\prime \prime}$ LW) tiene una estructura urbana compuesta de tres retículas. una que soporta físicamente al conjunto, otra que contiene la volumetría arquitectónica y una tercera trama vegetal asociada al sistema de riego, estratégicamente dispuesta en calles, parques y plazas (Cantón y Martinez 2009). El parque O'Higgins con una superficie de nueve hectáreas forma parte del conjunto de espacios verdes del área metropolitana de Mendoza. Es un área histórica y consolidada en cuanto a diseño y edad de las especies. Desde el punto de vista morfológico presenta un desarrollo longitudinal (800 m de largo y $200 \mathrm{~m}$ de ancho) con un eje central definido por una estructura abovedada conformada por árboles añosos de Fraxinus americana y Fraxinus excelsior (fresnos). La cobertura vegetal está integrada además, por masas boscosas de diversas especies, con baja proporción de prados abiertos en relación con los bosques y grupos laterales de arbustos distribuidos hacia los bordes. Aunque en el pasado el parque definía el límite oriente de la ciudad, en la actualidad se encuentra inserto en la trama urbana y con un eficiente comportamiento térmico en términos ambientales (Ruiz y Correa 2015). Su entorno tiene una densidad constructiva media ( 2 a $4 \mathrm{~m}^{3} / \mathrm{m}^{2}$ ) sin alturas de edificación homogéneas y con numerosos vacíos urbanos. El parque limita con la 


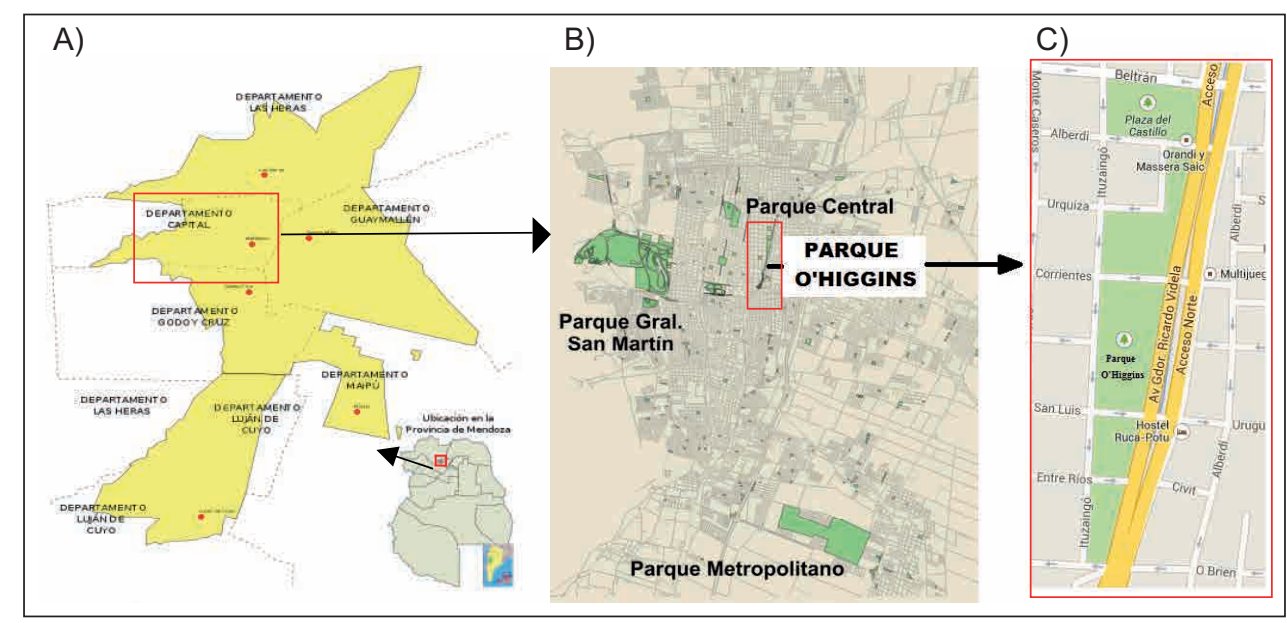

Fig. 2. A) Área de estudio dentro de la provincia de Mendoza. B) Ubicación del parque O’Higgins en el área metropolitana de mendoza. C) Detalle de la extensión del parque. Fuente: Wikipedia y Google maps. Adaptado por los autores

Avenida Gobernador Videla, uno de los principales accesos desde el norte hacia el centro de la ciudad. Esta avenida es también una ruta de tránsito intenso y constante durante todos los horarios a lo largo de todo el año. que constituye una fuente de ruido permanente para las edificaciones del lado oeste del parque (Fig. 2).

\section{Diseño experimental}

El diseño experimental plantea la realización de mediciones del ruido in situ durante verano e invierno. Se seleccionaron tres sectores dentro del parque (1.2.3). Para cada uno de los ellos se tomaron tres puntos de medición georreferenciados: a) en la cercanía de la fuente, b) centro del sector y c) en la cercanía del receptor (Fig. 3).

\section{Caracterización de la vegetación}

Para los tres sectores seleccionados se realizó la caracterización vegetal mediante un relevamiento cualicuantitativo en términos de especies y características dasonómicas. Se identificaron taxonómicamente las especies, se determinaron las características morfológicas y los atributos que reúnen en función de contribuir eficazmente en la mitigación del ruido como integrantes de una barrera vegetal.

Las variables consideradas son: género, especie y nombre común, tipo (caducifolia o perennifolia), origen (nativa o exótica), función (árbol o arbusto) y magnitud de desarrollo según la altura final alcanzada por el forestal en estado adulto $\left(1^{\mathrm{a}}, 2^{\mathrm{a}}, 3^{\mathrm{a}}\right)$ (Correa et al. 2007). Paralelamente, mediante el análisis de imágenes y fotografías aéreas se identificaron las

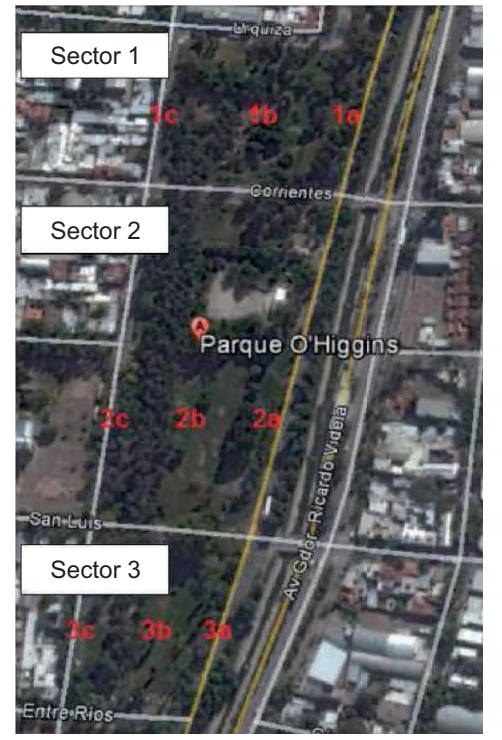

Fig. 3. Parque O'Higgins: sectores y puntos de medición de ruido. Fuente: Google earth 2014.

nubes de vegetación de cada sector, en particular las más densas, como se observa en la figura 4.

Para la caracterización de las distintas especies se aplicaron métodos dasométricos de medición a campo y de cálculo en gabinete (Cuadro I).

\section{Procedimiento de medición sonora}

El protocolo de mediciones acústicas seguido incluyó: medición de condiciones atmosféricas previas al registro de niveles de presión sonora y medición y 
Sector 1

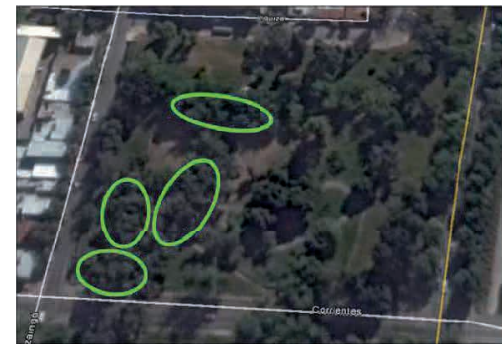

Sector 2

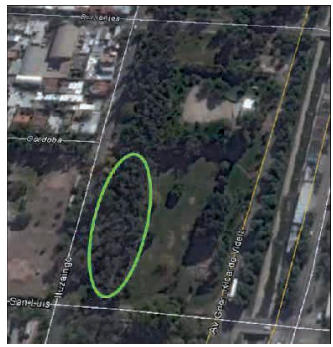

Sector 3

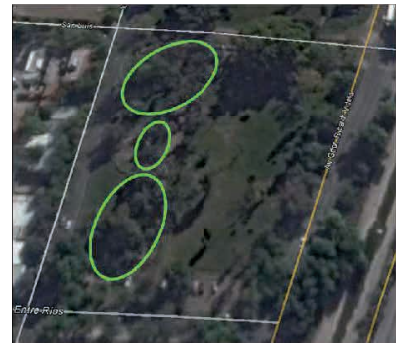

Fig. 4. Masas densas de vegetación para cada sector de medición. Fuente: google earth - imagen enero 2014.

registro simultáneos en los puntos seleccionados de niveles de presión sonora. La sistematización de los registros obtenidos se realizó mediante indicadores de niveles sonoros: nivel sonoro continuo equivalente $\mathrm{L}_{\text {eq }}$; niveles percentiles $\mathrm{L}_{10}, \mathrm{~L}_{50}$, L90 y moda; nivel mínimo, Lmin, y nivel máximo, Lmax, con ponderación.

El equipo utilizado constó de: sistema de posicionamiento global (GPS, por sus siglas en inglés) marca Garmin, modelo Legend Etrex, medidor de nivel sonoro portátil marca Extech Instruments modelo 407762 CLASE II, calibrador acústico marca Extech Instruments modelo 407769 según norma IEC942 tipo 2, termómetro digital marca Brymen modelo BM815, anemómetro marca Lutron modelo LM-8000, pantalla antiviento, trípode marca Benro modelo T800EX y cámara fotográfica digital marca Sony modelo DSC-W5 (Fig. 5).

\section{CUADRO I. CARACTERIZACIÓN VEGETAL. VARIABLES DASONÓMICAS}

\section{VARIABLES MEDIDAS}

1- Altura total en metros (h total):

Medida desde la base del tronco o fuste hasta la parte final del dosel o copa.

2- Altura de tronco en metros (h de tronco):

Medida desde la base del tronco o fuste hasta el inicio de la ramificación.

3- Altura de copa en metros (h de copa):

Medida desde el inicio de la ramificación y hasta el final del dosel o copa.

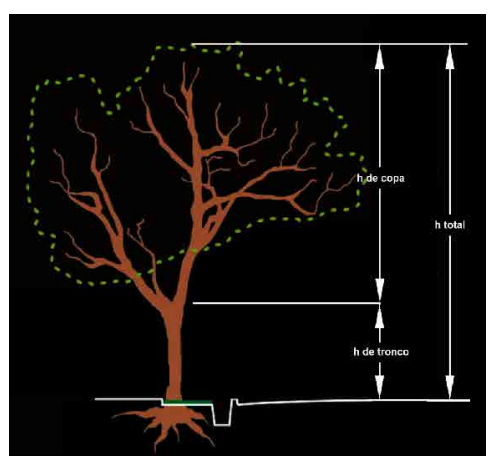

Diámetro de la copa (m): medida según su proyección en planta en las dos direcciones principales de acuerdo con el siguiente esquema y su fórmula:

Diámetro promedio $=\underline{\mathbf{D}_{\mathrm{P}}=(\mathrm{D}+\mathbf{d})}$

Siendo: $\quad \mathbf{D}=$ Diámetro mayor d = Diámetro menor

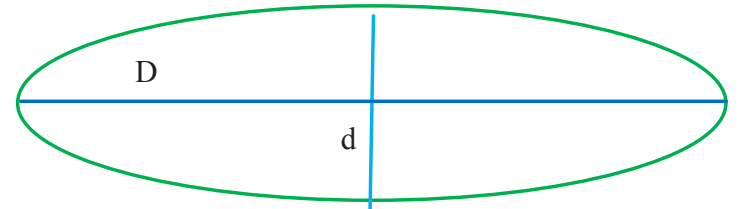

5- Relación tronco-copa (T/C): relación entre altura de tronco o fuste libre respecto a la copa o dosel (Martinez et al. 2006). 6- Volumen vegetal $\left(\mathrm{m}^{3}\right)$ : nubes de vegetación visualizadas a través de imágenes aéreas. Calculado a partir del radio y la altura de copa según la siguiente fórmula:

Volumen vegetal $=\pi \times \mathbf{r}^{2} \times \mathbf{h}_{\mathrm{c}}$

Siendo: $\quad \mathbf{r}=$ radio de copa $\mathbf{h}_{\mathrm{c}}=$ altura de copa 
A)

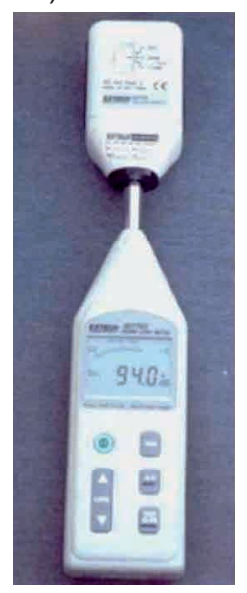

B)

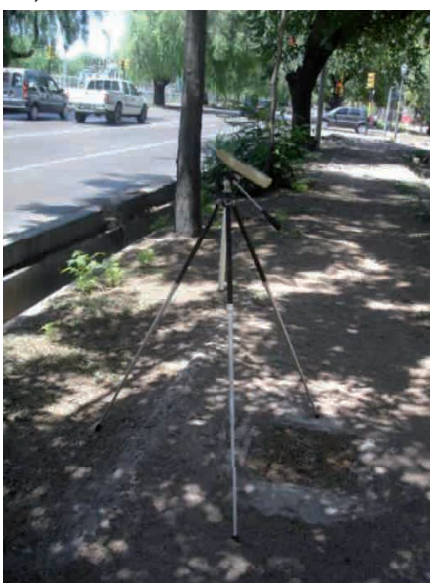

C)

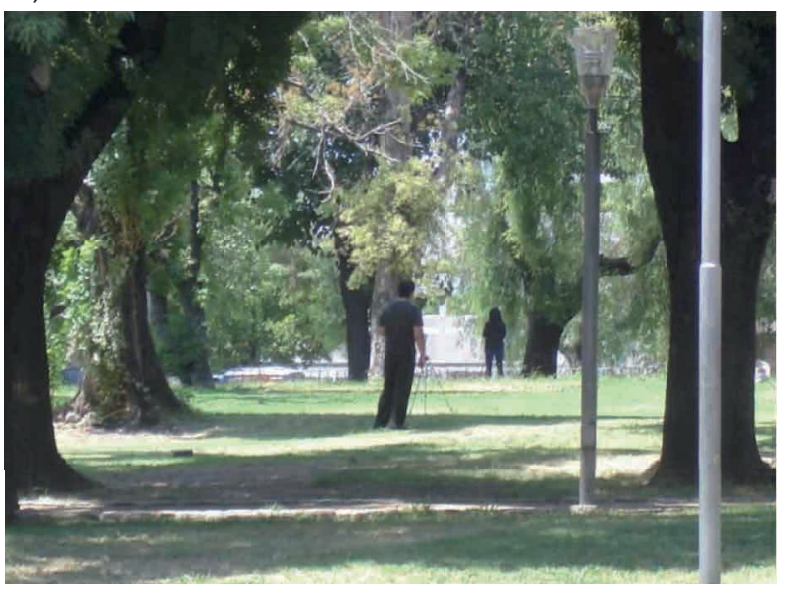

Fig. 5. Equipos de medición: A) medidor de nivel sonoro portátil marca Extech instruments modelo 407762 clase II y calibrador acústico marca Extech instruments modelo 407769, B) trípode marca Benro modelo T800EX, C) disposición de los operarios de los equipos

Las mediciones tanto acústicas como vehiculares se efectuaron en 2014 durante verano (mes de enero) e invierno (mes de agosto) para considerar la condición caduca o perenne de la vegetación y en días laborales para tener en cuenta el tránsito frecuente. Para velocidades del viento en el rango de 3 a $5 \mathrm{~m} / \mathrm{s}$ se protegió el micrófono con paravientos con el fin de evitar un aumento ficticio de los niveles medidos. En cada punto el equipo se ubicó separado de 1 a $2 \mathrm{~m}$ de superficies reflectantes que pudieran interferir (vehículos estacionados, carteles, señales de tránsito, etc.); a una altura de $1.20 \mathrm{~m}$ del suelo y a $90^{\circ}$ respecto de la línea del tránsito. Al comienzo de cada medición se registró hora de inicio y distancia desde el punto a la fuente de emisión. En cada estación de medición se tomaron lecturas separadas a intervalos de tiempo de 10 segundos durante lapos de 15 minutos, lo cual totaliza 90 registros por punto cada vez. A lo largo de un día de medición y para todos los puntos evaluados se totalizan 3240 registros (Fig. 6).
Las franjas horarias establecidas para las mediciones fueron:

- Franja matutina: de 08:00 a 09:00 h (mañana) y de $12: 30$ a $13: 30$ h (mediodía)

- Franja vespertina: de 17:30 a 18:30 h (tarde) y de 20:30 a 21:30 h (noche)

\section{Sistematización y cálculo de indicadores de niveles sonoros}

A partir de los valores registrados se calculó el indicador nivel sonoro continuo equivalente para cada punto, según las fórmulas especificadas en la versión 2016 de la Norma IRAM 4062 "Ruidos Molestos al Vecindario" (IRAM 2016). Mediante procesamiento estadístico se obtuvo los restantes indicadores de presión sonora.

Para el cálculo del nivel sonoro representativo $L_{\text {eq }}$ se emplea la siguiente fórmula:

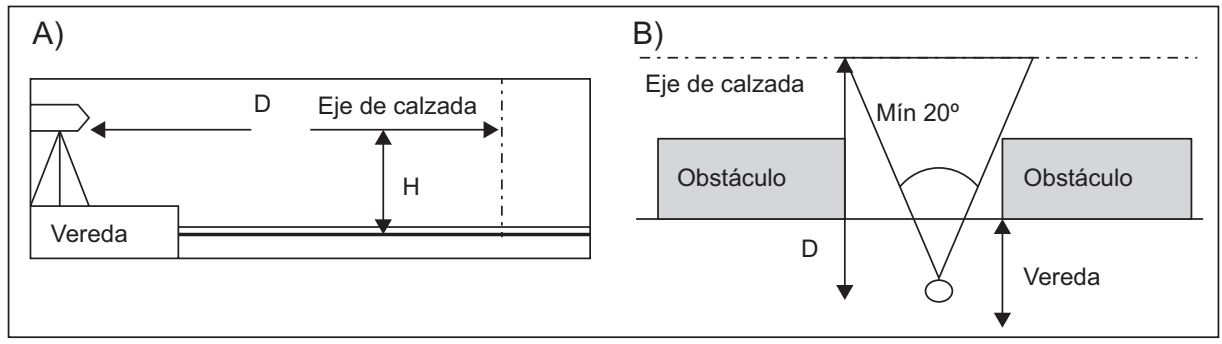

Fig. 6. Ubicación de la estación de medición: A) vista en corte. B) vista en planta. Fuente: Boschi y Muñoz-Vargas (2007) 
$\mathrm{L}_{\mathrm{eq}}=10 \log \frac{1}{\mathrm{~T}} \sum \mathrm{t}_{\mathrm{i}}(10)^{\mathrm{L}_{1} / 10} \mathrm{~dB}(\mathrm{~A})$

Siendo: $t_{i}$ el tiempo de observación durante el cual el nivel sonoro es Li.

Según la norma se establece que los instrumentos a utilizar deben ser del tipo integrador, pero dadas las características particulares de los niveles sonoros a registrar no es conveniente utilizar esta clase de decibelímetros. Esto es así porque en los puntos "b" y "c" de cada sector se deben descartar los ruidos originados por el pasaje de vehículos de las otras calles que no son la Avenida Gobernador Videla. En consecuencia se utilizaron sonómetros convencionales no integradores que permiten descartar valores (Recuero-López 1999).

Los niveles medidos in situ en cada punto fueron también estimados calculando la atenuación del ruido de tráfico irradiado por una línea de vehículos de motor que circula sobre una autopista mediante la siguiente fórmula (Harris 1998):

$\mathrm{L}_{\mathrm{eq}}=\mathrm{L}_{\mathrm{er} \mathrm{ref}}-10 \log (\mathrm{r} / \mathrm{ref})$

Siendo: $\mathrm{L}_{\mathrm{eq}}$ : nivel sonoro continuo equivalente calculado a una distancia $r$ de la fuente sonora mediante la fórmula precedente.

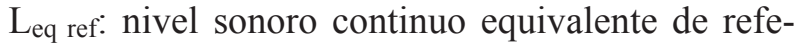
rencia. medido in situ en los puntos 1a, 2a y $3 \mathrm{a}$, respectivamente.

$r$ : distancia entre fuente sonora y los puntos donde se quiere calcular la atenuación del sonido.

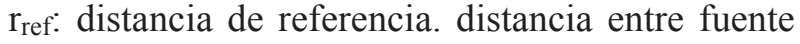
sonora y los puntos $1 \mathrm{a}, 2 \mathrm{a}$ y $3 \mathrm{a}$, respectivamente.

Como la fórmula de Harris (1998) no contempla la atenuación debido a la atmósfera y al suelo, se utilizó para su cálculo el término adicional denominado Atenuación total debida a todos los aportes $\left(\mathrm{A}_{\text {tot }}\right)$. Éste además de incluir la atenuación por refracción en el segundo término de la fórmula referida, tiene en cuenta los factores que disminuyen la mitigación del ruido cuando se propaga en ambientes abiertos, dado que los niveles sonoros producidos por el tráfico rodado presentan mayor propagación en áreas no pavimentadas relativamente abiertas. Para este cálculo se utilizó la norma internacional "ISO 9613-2 Acoustics-Attenuation of sound during propagation outdoors -Part 2: General Method of calculation" versión 2016 (ISO 2016):

$\mathrm{A}_{\text {tot }}=\mathrm{A}_{\text {refr }}+\mathrm{A}_{\text {atm }}+\mathrm{A}_{\text {suelo }}+\mathrm{A}_{\text {barrera }}$

Siendo:
$\mathrm{A}_{\text {tot: }}$ atenuación total debida a todos los aportes.

$\mathrm{A}_{\text {refr: }}$ atenuación por refracción.

$\mathrm{A}_{\text {atm: }}$ : atenuación debida a la absorción molecular de la atmósfera.

$\mathrm{A}_{\text {suelo: }}$ atenuación debida al efecto suelo.

$A_{\text {barrera: }}$ pérdida por inserción de una barrera.

\section{Conteo vehicular}

En los puntos 1a, 2a y 3a lindantes a la Avenida Gobernador Videla se realizó un conteo vehicular durante las mediciones realizadas en las estaciones de invierno (mes de agosto) y verano (mes de enero) del año 2014, en forma simultánea a las mediciones de niveles de presión sonora a fin de correlacionar la incidencia del flujo del tránsito con los niveles sonoros registrados.

\section{RESULTADOS}

Se presentan los resultados obtenidos en los tres sectores seleccionados del parque, considerando el relevamiento vegetal y los niveles sonoros medidos.

\section{Caracterización y diagnóstico de la vegetación}

En los tres sectores evaluados se relevó un total de 287 individuos pertenecientes a 44 especies (Fig. 7). Para los distintos sectores, la representatividad porcentual de especies caducifolias varía entre $64 \%$ a $84 \%$, mientras que para perennes. la variación está en el orden del $16 \%$ al $36 \%$. Con respecto al origen, las especies exóticas representan el $93 \%$ al $99 \%$ y las nativas sólo del $1 \%$ al $7 \%$. Se observan mayores porcentajes de especies exóticas y del tipo caducifolias en todos los sectores.

El mayor número de individuos para el sector 1 corresponde a las especies Fraxinus excelsior y Casuarina cuningamiana; para el sector 2 se observa mayor abundancia de Fraxinus excelsior y Populus alba y para el sector 3, Fraxinus excelsior y Morus alba. Cabe destacar la preponderancia de Fraxinus excelsior "fresno europeo" dado que constituye la alineación de árboles que enmarca el sendero central del parque en toda su longitud.

Los valores observados indican un alto porcentaje de especies caducifolias. Sólo el sector 1 manifiesta el mayor valor de perennes (36\%). El elevado porcentaje de especies exóticas introducidas de otros ambientes y generalmente con altos requerimientos hídricos, implica un mayor consumo del recurso agua. Es mínimo el porcentaje de especies nativas encontradas que ofrecerían mejores condiciones de adaptación a la aridez. Esto trae aparejado un 


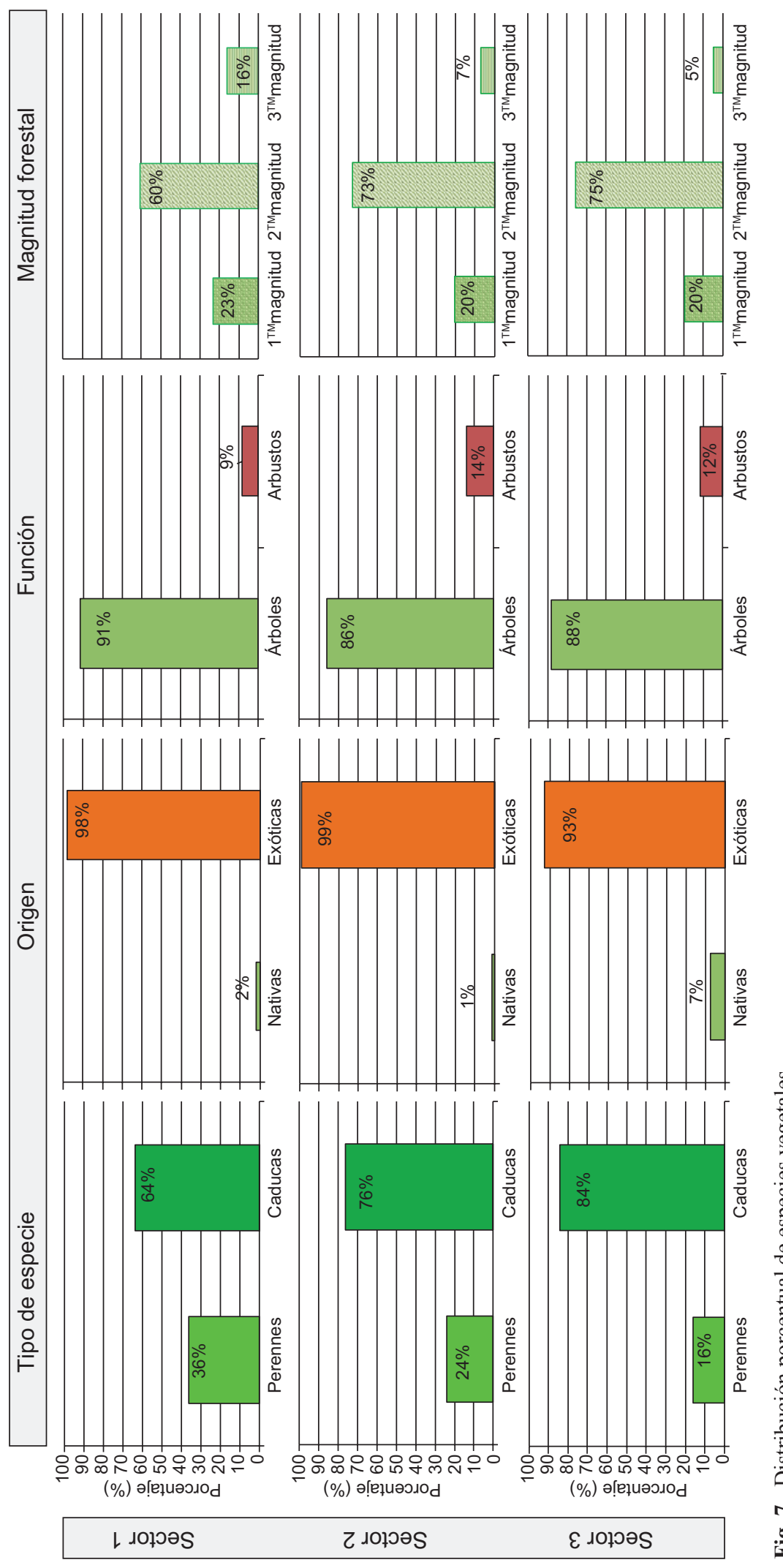


potencial estado de estrés hídrico que afectaría el crecimiento, buen estado fitosanitario y longevidad de las especies. Se observa que sólo el sector 3 presenta el mayor porcentaje de especies nativas (7\%).

En el sector 1, el $91 \%$ pertenece a 14 especies arbóreas y el $9 \%$ a dos especies de arbustos. Cydonia oblonga predomina en la población de arbustos. En la vegetación arbórea, el $60 \%$ corresponde a siete especies de segunda magnitud, $22 \%$ a tres especies de primera magnitud y $18 \%$ a cuatro especies de tercera magnitud. Cabe aclarar que el término "magnitud forestal" hace referencia a la altura final que alcanzan los árboles en su estado adulto según sus características genéticas, y que se corresponden aproximadamente a los 20 años desde su plantación. La primera magnitud forestal corresponde a las especies arbóreas cuya altura final supera los $15 \mathrm{~m}$, la segunda magnitud a los forestales de entre 10 y $15 \mathrm{~m}$ de altura final y la tercera magnitud a aquellas especies que registran alturas inferiores a $10 \mathrm{~m}$ en su estado adulto.

En el sector 2, el $86 \%$ corresponde a 17 especies de árboles y $14 \%$ a cinco especies de arbustos, donde Nerium oleander tiene la mayor representatividad. Considerando la vegetación arbórea, el 73 \% corresponde a 11 especies de segunda magnitud, $20 \%$ a ocho especies de primera magnitud y siete $\%$ a $1 \mathrm{a}$ tercera magnitud.

En el sector 3, el $89 \%$ corresponde a 14 especies de árboles y $11 \%$ a cinco especies de arbustos. Las especies Punica granatum, Spiraea cantoniensis y Viburnum tinus son las especies predominantes para el estrato arbustivo y cuantitativamente, se ha relevado el mismo número de ejemplares para cada especie.

El $74 \%$ de los árboles identificados se agrupan en cinco especies de segunda magnitud, $20 \%$ corresponden a ocho especies de primera magnitud y $6 \%$ corresponde a la tercera magnitud.

Para los tres sectores Fraxinus excelsior es la especie más abundante para la categoría árboles y comparativamente el porcentaje de arbustos es considerablemente menor, siendo el sector 2 el que posee mayor presencia.

El cálculo del volumen vegetal realizado teniendo en cuenta las nubes o masas de vegetación seleccionadas para cada sector y tomando una altura de copa promedio de seis metros, muestra que el sector 2 es el que presenta mayor volumen de vegetación (Cuadro II).

CUADRO II. VOLUMEN VEGETAL SEGÚN MASAS DE VEGETACIÓN CUANTIFICADAS

\begin{tabular}{lcc}
\hline Sector & $\begin{array}{c}\text { Superficie total } \\
\text { del sector (ha.) }\end{array}$ & $\begin{array}{c}\text { Volumen de masas de } \\
\text { vegetación }\left(\mathrm{m}^{3}\right)\end{array}$ \\
\hline Sector 1 & 2.2 & $\mathbf{1 5 0 6 8}$ \\
Sector 2 & 3.8 & $\mathbf{2 6 3 9 4}$ \\
Sector 3 & 1.4 & $\mathbf{9 8 6 2}$ \\
\hline
\end{tabular}

Para cada sector las mediciones dasométricas de especies cuantitativamente representativas indican que la mayoría de los árboles son ejemplares de segunda magnitud forestal de Fraxinus exelsior, con una relación tronco-copa $(\mathrm{T} / \mathrm{C})=1 / 4 \mathrm{y}$ un volumen vegetal de $730 \mathrm{~m}^{3}$ a $1030 \mathrm{~m}^{3}$.

Los arbustos de los distintos sectores son de tercera magnitud, presentan una relación $\mathrm{T} / \mathrm{C}=1 / 2$ y un volumen vegetativo de $38 \mathrm{~m}^{3}$ a $95 \mathrm{~m}^{3}$. Se encuentran distribuidos en forma aislada sin presentar solapamiento de copas.

\section{Resultados de las mediciones sonoras (verano $e$ invierno)}

Para analizar las mediciones sonoras se ha considerado la cantidad de vehículos contabilizada en los puntos más cercanos a la avenida (punto a). Los resultados obtenidos en verano e invierno en las correspondientes franjas horarias se representan en el cuadro III. La mayor cantidad de vehículos

CUADRO III. CONTEO VEHICULAR ESTACIONAL PARA CADA SECTOR

\begin{tabular}{|c|c|c|c|c|c|c|c|c|c|c|c|c|}
\hline \multirow{3}{*}{$\begin{array}{l}\text { Tipo de } \\
\text { vehículo }\end{array}$} & \multicolumn{4}{|c|}{ Sector 1} & \multicolumn{4}{|c|}{ Sector 2} & \multicolumn{4}{|c|}{ Sector 3} \\
\hline & \multicolumn{2}{|c|}{ Verano } & \multicolumn{2}{|c|}{ Invierno } & \multicolumn{2}{|c|}{ Verano } & \multicolumn{2}{|c|}{ Invierno } & \multicolumn{2}{|c|}{ Verano } & \multicolumn{2}{|c|}{ Invierno } \\
\hline & $\%$ & cantidad & $\%$ & cantidad & $\%$ & cantidad & $\%$ & cantidad & $\%$ & cantidad & $\%$ & cantidad \\
\hline $\begin{array}{l}\text { Autos y } \\
\text { utilitarios }\end{array}$ & 86 & 1810 & 90 & 1680 & 89 & 1639 & 89 & 1736 & 91 & 1758 & 93 & 2097 \\
\hline $\begin{array}{l}\text { Camiones y } \\
\text { ómnibus }\end{array}$ & 4 & 92 & 5 & 90 & 3 & 58 & 4 & 71 & 3 & 52 & 2 & 51 \\
\hline Motos & 10 & 214 & 5 & 94 & 8 & 148 & 7 & 146 & 6 & 124 & 5 & 117 \\
\hline
\end{tabular}


corresponde a la categoría de autos utilitarios, sin variaciones significativas. Las motos registran menor presencia en invierno y los camiones y ómnibus muestran cantidades similares en ambas estaciones.

Los resultados de los indicadores de niveles sonoros para cada punto, sector y franjas horarias establecidas se observan en el cuadro IV.

Examinando los percentiles, cada uno presenta alta homogeneidad para las distintas franjas horarias en ambas estaciones y para un mismo punto de medición. Al considerar la similitud de valores de niveles sonoros equivalentes en las diferentes franjas horarias, la figura 8 muestra los valores promedio de los mismos para cada punto. El análisis indica disminuciones desde el punto "a" al "c" para ambas estaciones en los tres sectores. Los valores son mayores en invierno en la mayoría de los puntos, en correspondencia con la menor biomasa por receso vegetal. La excepción se presenta en el punto $b$ del sector 3 .

\section{Análisis estadístico}

Para cada sector se consideran los tres puntos de medición y se realiza el análisis de la varianza (ANDEVA) en las dos estaciones evaluadas mediante el programa InfoStat (Cuadro V). Se aplica un nivel de significancia $\alpha$ (alfa) del orden de 0.05 . Los resultados del ANDEVA indican diferencias significativas entre las medias de los registros para cada sector y cada punto. Para visualizar dichas diferencias se realizó la prueba de Tuckey a modo de crear intervalos de confianza para todas las diferencias en parejas entre las medias de los factores analizados.

Se toma en todos los casos, las siguientes hipótesis:

$\mathrm{H}_{0}$ : Todas las mediciones de nivel de ruido de la población son iguales.

$\mathrm{H}_{1}$ : No todas las mediciones de nivel de ruido de la población son iguales.

Se toma la tabla de valores de la distribución $\mathrm{F}$ de Fisher

Los sectores resaltados en el cuadro $\mathbf{V}$ superan el valor crítico, por tanto se acepta la hipótesis alternativa $\mathrm{H}_{1}$ permitiendo corroborar diferencias de niveles de ruido. En los demás casos se aprueba la hipótesis nula $H_{0}$ (para $\alpha=0.05$ ). Se observan diferencias significativas en los puntos "c" del sector 1 y 2 . La diferencia en el punto "a" del sector 2 se debe a la fluctuación del tráfico vehicular al ser el punto más cercano a la calle.

Como se ha mencionado, los niveles sonoros en cada punto fueron estimados calculando la atenuación del ruido de tráfico cuando se propaga en un espacio abierto. Los mismos ( $\mathrm{L}_{\text {eq }}$ calculado) se presentan en el cuadro VI junto a los niveles sonoros medidos in situ ( $\mathrm{L}_{\mathrm{eq}}$ medido).

Se observa que en todos los sectores existe correlación entre los valores medidos y los calculados. En el sector 1 los valores medidos resultan ser mayores que los calculados. En el punto "c" en invierno se comprueba la mayor diferencia: $2.7 \mathrm{~dB}(\mathrm{~A})$, en verano dicha diferencia es de $1.5 \mathrm{~dB}(\mathrm{~A})$.

En el sector 2 los valores medidos resultan menores que los calculados en el punto "b" aunque por un escaso margen de $0.6 \mathrm{~dB}(\mathrm{~A})$ en verano $\mathrm{y}$ $0.4 \mathrm{~dB}(\mathrm{~A})$ en invierno. En el punto "c" los valores medidos resultan mayores que los calculados. Aquí la diferencia para invierno es de $1.7 \mathrm{~dB}(\mathrm{~A})$ y de 1.0 $\mathrm{dB}(\mathrm{A})$ para verano.

El sector 3 en verano presenta valores medidos mayores que los calculados y en invierno ocurre lo contrario. En el punto " $b$ " en verano se presenta una diferencia de $1.1 \mathrm{~dB}(\mathrm{~A})$ y en invierno de $1.0 \mathrm{~dB}(\mathrm{~A})$.

\section{DISCUSIÓN}

En zonas urbanas de elevado tránsito vehicular como el caso estudiado en este trabajo que refiere a una avenida de dos manos con cuatro carriles cada una, y que une de norte a sur el área metropolitana de Mendoza, la presencia de barreras acústicas del tipo natural o vegetal (espacios verdes) constituye una estrategia viable para mitigar los elevados niveles sonoros. Esta presencia permite además conseguir adicionalmente todos los beneficios ambientales que aportan dichas barreras.

La implementación de barreras vegetales en otros países es frecuente para el control del ruido en la etapa de propagación (Pigasse y Kragh 2011). Sin embargo, cuando se analiza el funcionamiento de un espacio verde como barrera acústica, deben considerase los enfoques a favor de su eficacia (Samara y Tsitsoni 2007, Demaria-Castañeda et al. 2014 ) y los que se cree que no cumplan su función adecuadamente (Higueras 2006). Estas discrepancias entre investigaciones provienen de la dificultad de determinar el proceso físico que siguen las ondas sonoras al atravesar una masa vegetal. En atención a estos motivos, se realizó in situ la evaluación de la eficiencia del parque O'Higgins como barrera acústica.

En la ciudad de Mendoza, como en el resto de la provincia en general, se observa un constante aumento del parque automotor en la última década. La cercanía de zonas residenciales respecto de arterias 
CUADRO IV. INDICADORES DE NIVELES SONOROS DE VERANO E INVIERNO EN LOS PUNTOS DE CADA SECTOR

\begin{tabular}{|c|c|c|c|c|c|c|c|}
\hline \multicolumn{8}{|c|}{ SECTOR 1} \\
\hline \multirow{3}{*}{$\begin{array}{l}\text { Franja } \\
\text { horaria }\end{array}$} & \multirow{3}{*}{ Indicador } & \multicolumn{6}{|c|}{ Puntos de medición } \\
\hline & & \multicolumn{2}{|c|}{$1 \mathrm{a}$} & \multicolumn{2}{|c|}{$1 \mathrm{~b}$} & \multicolumn{2}{|c|}{$1 \mathrm{c}$} \\
\hline & & $\begin{array}{c}\text { Verano } \\
{[\mathrm{dB}(\mathrm{A})]}\end{array}$ & $\begin{array}{l}\text { Invierno } \\
{[\mathrm{dB}(\mathrm{A})]}\end{array}$ & $\begin{array}{c}\text { Verano } \\
{[\mathrm{dB}(\mathrm{A})]}\end{array}$ & $\begin{array}{l}\text { Invierno } \\
{[\mathrm{dB}(\mathrm{A})]}\end{array}$ & $\begin{array}{c}\text { Verano } \\
{[\mathrm{dB}(\mathrm{A})]}\end{array}$ & $\begin{array}{l}\text { Invierno } \\
{[\mathrm{dB}(\mathrm{A})]}\end{array}$ \\
\hline \multirow[t]{7}{*}{ Mañana } & $\mathrm{L}_{\mathrm{eq}}$ & 72.0 & 72.9 & 58.9 & 63.5 & 55.6 & 57.4 \\
\hline & $\mathrm{L}_{10}$ & 75.5 & 76.4 & 61.5 & 66.9 & 58.0 & 58.3 \\
\hline & $\mathrm{L}_{50}$ & 69.0 & 69.9 & 58.0 & 61.1 & 54.9 & 57.3 \\
\hline & $\mathrm{L}_{90}$ & 62.4 & 63.5 & 54.6 & 55.3 & 51.8 & 56.4 \\
\hline & Moda & 66.5 & 66.6 & 56.4 & 59.0 & 53.0 & 57.4 \\
\hline & Lmin & 59.2 & 63.3 & 52.5 & 55.7 & 52.3 & 55.4 \\
\hline & Lmax & 82.2 & 80.1 & 63.8 & 78.7 & 61.2 & 58.3 \\
\hline \multirow[t]{7}{*}{ Mediodía } & $\mathrm{L}_{\mathrm{eq}}$ & 71.6 & 73.2 & $\mathbf{5 7 . 0}$ & 60.1 & 53.5 & 56.6 \\
\hline & $\mathrm{L}_{10}$ & 75.2 & 76.7 & 59.6 & 62.7 & 55.0 & 58.3 \\
\hline & $\mathrm{L}_{50}$ & 68.4 & 70.2 & 56.2 & 59.2 & 53.3 & 56.3 \\
\hline & $\mathrm{L}_{90}$ & 61.6 & 63.7 & 52.8 & 55.7 & 51.7 & 54.3 \\
\hline & Moda & 73.2 & 67.8 & 57.3 & 56.0 & 52.9 & 56.1 \\
\hline & Lmin & 58.5 & 61.0 & 51.5 & 54.6 & 51.0 & 54.1 \\
\hline & Lmax & 80.8 & 82.3 & 62.3 & 67.3 & 56.6 & 58.9 \\
\hline \multirow[t]{7}{*}{ Tarde } & $\mathrm{L}_{\mathrm{eq}}$ & 72.3 & 72.9 & 59.1 & 59.6 & 55.3 & 56.1 \\
\hline & $\mathrm{L}_{10}$ & 75.9 & 76.4 & 62.0 & 62.0 & 58.1 & 57.8 \\
\hline & $\mathrm{L}_{50}$ & 68.6 & 69.8 & 57.9 & 58.9 & 54.2 & 55.8 \\
\hline & $\mathrm{L}_{90}$ & 61.4 & 63.1 & 53.9 & 55.8 & 50.4 & 53.8 \\
\hline & Moda & 63.8 & 68.8 & 57.0 & 63.0 & 53.8 & 54.1 \\
\hline & Lmin & 57.0 & 59.6 & 52.3 & 53.6 & 51.6 & 53.1 \\
\hline & Lmax & 81.7 & 80.8 & 70.1 & 64.9 & 63.7 & 58.6 \\
\hline \multirow[t]{7}{*}{ Noche } & $\mathrm{L}_{\mathrm{eq}}$ & 72.1 & 71.9 & 58.1 & 58.6 & 53.2 & 56.8 \\
\hline & $\mathrm{L}_{10}$ & 75.7 & 75.4 & 60.5 & 61.0 & 55.5 & 58.5 \\
\hline & $\mathrm{L}_{50}$ & 68.8 & 68.8 & 57.4 & 57.9 & 52.6 & 56.6 \\
\hline & $\mathrm{L}_{90}$ & 61.9 & 62.1 & 54.3 & 54.7 & 49.6 & 54.7 \\
\hline & Moda & 67.8 & 63.5 & 57.7 & 57.4 & 51.8 & 57.8 \\
\hline & Lmin & 58.3 & 58.7 & 51.3 & 52.0 & 46.1 & 52.3 \\
\hline & Lmax & 80.5 & 79.7 & 63.1 & 63.5 & 59.5 & 59.2 \\
\hline \multicolumn{8}{|c|}{ SECTOR 2} \\
\hline \multirow{3}{*}{$\begin{array}{l}\text { Franja } \\
\text { horaria }\end{array}$} & \multirow{3}{*}{ Indicador } & \multicolumn{6}{|c|}{ Puntos de medición } \\
\hline & & \multicolumn{2}{|c|}{$2 \mathrm{a}$} & \multicolumn{2}{|c|}{$2 b$} & \multicolumn{2}{|c|}{$2 c$} \\
\hline & & $\begin{array}{c}\text { Verano } \\
{[\mathrm{dB}(\mathrm{A})]}\end{array}$ & $\begin{array}{l}\text { Invierno } \\
{[\mathrm{dB}(\mathrm{A})]}\end{array}$ & $\begin{array}{c}\text { Verano } \\
{[\mathrm{dB}(\mathrm{A})]}\end{array}$ & $\begin{array}{l}\text { Invierno } \\
{[\mathrm{dB}(\mathrm{A})]}\end{array}$ & $\begin{array}{c}\text { Verano } \\
{[\mathrm{dB}(\mathrm{A})]}\end{array}$ & $\begin{array}{l}\text { Invierno } \\
{[\mathrm{dB}(\mathrm{A})]}\end{array}$ \\
\hline \multirow[t]{7}{*}{ Mañana } & $\mathrm{L}_{\mathrm{eq}}$ & 72.9 & 76.2 & 60.3 & 62.2 & 58.8 & 58.6 \\
\hline & $\mathrm{L}_{10}$ & 76.3 & 79.4 & 62.6 & 65.4 & 61.6 & 60.6 \\
\hline & $\mathrm{L}_{50}$ & 67.4 & 70.0 & 59.7 & 60.7 & 57.7 & 58.2 \\
\hline & $\mathrm{L}_{90}$ & 58.5 & 60.6 & 56.8 & 55.9 & 53.7 & 55.7 \\
\hline & Moda & 58.0 & 74.0 & 59.6 & 62.3 & 57.0 & 58.4 \\
\hline & Lmin & 56.0 & 57.8 & 56.2 & 52.8 & 53.4 & 55.4 \\
\hline & Lmax & 82.4 & 85.8 & 67.7 & 75.0 & 66.0 & 64.0 \\
\hline
\end{tabular}




\begin{tabular}{llllllll}
\hline Mediodía & L & $\mathbf{7 3 . 7}$ & $\mathbf{7 4 . 0}$ & $\mathbf{5 7 . 8}$ & $\mathbf{6 0 . 9}$ & $\mathbf{5 5 . 4}$ & $\mathbf{5 8 . 9}$ \\
& L $_{10}$ & 76.9 & 77.6 & 60.8 & 63.6 & 56.7 & 60.5 \\
& L $_{50}$ & 67.7 & 70.6 & 56.6 & 60.0 & 55.2 & 58.7 \\
& L90 & 58.4 & 63.7 & 52.4 & 56.3 & 53.6 & 56.8 \\
& Moda & 69.1 & 69.4 & 57.0 & 61.2 & 54.3 & 58.6 \\
& Lmin & 56.2 & 60.2 & 51.5 & 54.3 & 52.1 & 54.1 \\
& Lmax & 82.3 & 81.0 & 64.3 & 70.0 & 58.0 & 60.9 \\
\hline \multirow{2}{*}{ Tarde } & Leq & $\mathbf{7 2 . 6}$ & $\mathbf{7 4 . 9}$ & $\mathbf{5 7 . 7}$ & $\mathbf{5 8 . 9}$ & $\mathbf{5 4 . 9}$ & $\mathbf{5 8 . 7}$ \\
& L & 76.0 & 78.3 & 60.4 & 61.5 & 56.4 & 60.6 \\
& L50 & 67.3 & 69.3 & 56.8 & 58.0 & 54.7 & 58.4 \\
& L90 & 58.5 & 60.3 & 53.2 & 54.6 & 52.9 & 53.7 \\
& Moda & 63.3 & 78.2 & 55.2 & 60.7 & 55.9 & 58.4 \\
& Lmin & 55.5 & 56.0 & 51.2 & 52.8 & 52.0 & 54.4 \\
& Lmax & 79.9 & 81.8 & 61.7 & 63.2 & 57.0 & 61.7 \\
\hline \multirow{2}{*}{ Loche } & L & $\mathbf{7 1 . 9}$ & $\mathbf{7 3 . 8}$ & $\mathbf{5 6 . 9}$ & $\mathbf{6 0 . 2}$ & $\mathbf{5 4 . 1}$ & $\mathbf{5 8 . 4}$ \\
& L & 75.2 & 77.1 & 59.7 & 62.9 & 57.0 & 61.2 \\
& L50 & 66.3 & 68.0 & 55.9 & 59.2 & 53.1 & 57.4 \\
& L & 57.4 & 58.9 & 52.0 & 55.4 & 49.2 & 53.7 \\
& Moda & 74.2 & 66.8 & 56.9 & 60.9 & 53.4 & 55.2 \\
& Lmin & 51.9 & 53.3 & 49.9 & 52.8 & 47.4 & 51.9 \\
& Lmax & 80.3 & 80.9 & 61.3 & 64.3 & 59.6 & 63.6 \\
\hline
\end{tabular}

\begin{tabular}{|c|c|c|c|c|c|c|c|}
\hline \multirow{3}{*}{$\begin{array}{l}\text { Franja } \\
\text { horaria }\end{array}$} & \multirow{3}{*}{ Indicador } & \multicolumn{6}{|c|}{ Puntos de medición } \\
\hline & & \multicolumn{2}{|c|}{$3 a$} & \multicolumn{2}{|c|}{$3 b$} & \multicolumn{2}{|c|}{$3 \mathrm{c}$} \\
\hline & & $\begin{array}{c}\text { Verano } \\
{[\mathrm{dB}(\mathrm{A})]}\end{array}$ & $\begin{array}{l}\text { Invierno } \\
{[\mathrm{dB}(\mathrm{A})]}\end{array}$ & $\begin{array}{c}\text { Verano } \\
{[\mathrm{dB}(\mathrm{A})]}\end{array}$ & $\begin{array}{l}\text { Invierno } \\
{[\mathrm{dB}(\mathrm{A})]}\end{array}$ & $\begin{array}{c}\text { Verano } \\
{[\mathrm{dB}(\mathrm{A})]}\end{array}$ & $\begin{array}{l}\text { Invierno } \\
{[\mathrm{dB}(\mathrm{A})]}\end{array}$ \\
\hline \multirow[t]{7}{*}{ Mañana } & $\mathrm{L}_{\mathrm{eq}}$ & 74.0 & 76.2 & 62.0 & 61.6 & 56.7 & 58.2 \\
\hline & $\mathrm{L}_{10}$ & 77.5 & 79.6 & 64.3 & 64.0 & 58.9 & 59.9 \\
\hline & $\mathrm{L}_{50}$ & 69.6 & 71.0 & 61.4 & 60.9 & 56.2 & 57.8 \\
\hline & $\mathrm{L}_{90}$ & 61.6 & 62.5 & 58.6 & 57.9 & 53.5 & 55.8 \\
\hline & Moda & 75.4 & 76.9 & 61.2 & 63.0 & 55.7 & 59.7 \\
\hline & Lmin & 56.9 & 58.9 & 58.3 & 55.5 & 50.5 & 52.2 \\
\hline & Lmax & 79.0 & 81.5 & 70.2 & 65.7 & 63.0 & 61.9 \\
\hline \multirow[t]{7}{*}{ Mediodía } & $\mathrm{L}_{\mathrm{eq}}$ & 74.0 & 74.2 & 61.2 & 63.9 & 57.7 & 58.0 \\
\hline & $\mathrm{L}_{10}$ & 77.4 & 77.7 & 64.1 & 66.9 & 59.4 & 59.1 \\
\hline & $\mathrm{L}_{50}$ & 69.1 & 70.4 & 60.0 & 62.5 & 57.5 & 57.8 \\
\hline & $\mathrm{L}_{90}$ & 60.7 & 63.1 & 55.8 & 58.1 & 55.5 & 56.5 \\
\hline & Moda & 73.0 & 75.2 & 58.1 & 60.7 & 58.9 & 57.3 \\
\hline & Lmin & 56.4 & 57.6 & 53.3 & 56.0 & 53.4 & 56.1 \\
\hline & Lmax & 86.4 & 83.5 & 72.4 & 73.2 & 59.6 & 61.2 \\
\hline \multirow[t]{7}{*}{ Tarde } & $\mathrm{L}_{\mathrm{eq}}$ & 72.9 & 74.9 & 62.0 & 60.3 & 56.8 & 58.5 \\
\hline & $\mathrm{L}_{10}$ & 76.4 & 78.4 & 65.2 & 62.9 & 58.8 & 60.1 \\
\hline & $\mathrm{L}_{50}$ & 68.3 & 70.6 & 60.5 & 59.4 & 56.4 & 58.3 \\
\hline & $\mathrm{L}_{90}$ & 60.2 & 62.8 & 55.8 & 55.9 & 54.0 & 56.5 \\
\hline & Moda & 73.3 & 76.5 & 59.2 & 61.2 & 56.0 & 57.1 \\
\hline & Lmin & 56.1 & 57.5 & 55.1 & 52.9 & 52.8 & 55.4 \\
\hline & Lmax & 84.6 & 80.6 & 73.2 & 65.7 & 62.6 & 61.6 \\
\hline \multirow[t]{7}{*}{ Noche } & $\mathrm{L}_{\mathrm{eq}}$ & 73.1 & 73.6 & 62.3 & 58.9 & 57.0 & 56.5 \\
\hline & $\mathrm{L}_{10}$ & 76.3 & 76.8 & 65.1 & 61.7 & 59.0 & 58.4 \\
\hline & $\mathrm{L}_{50}$ & 66.9 & 67.6 & 61.2 & 57.9 & 56.6 & 56.1 \\
\hline & $\mathrm{L}_{90}$ & 57.6 & 58.5 & 57.3 & 54.1 & 54.2 & 53.8 \\
\hline & Moda & 72.4 & 73.9 & 62.5 & 58.8 & 57.0 & 57.0 \\
\hline & Lmin & 51.9 & 53.3 & 53.1 & 50.5 & 52.8 & 52.8 \\
\hline & Lmax & 79.0 & 78.0 & 67.2 & 63.8 & 58.9 & 58.9 \\
\hline
\end{tabular}

$\mathrm{L}_{\mathrm{eq}}=$ nivel sonoro continuo equivalente, $\mathrm{L}_{10}=$ nivel percentil $10, \mathrm{~L}_{50}=$ nivel percentil 50 ,

$\mathrm{L}_{90}=$ nivel percentil 90, Lmin= nivel sonoro mínimo, $\mathrm{Lmax}=$ nivel sonoro máximo con ponderación 

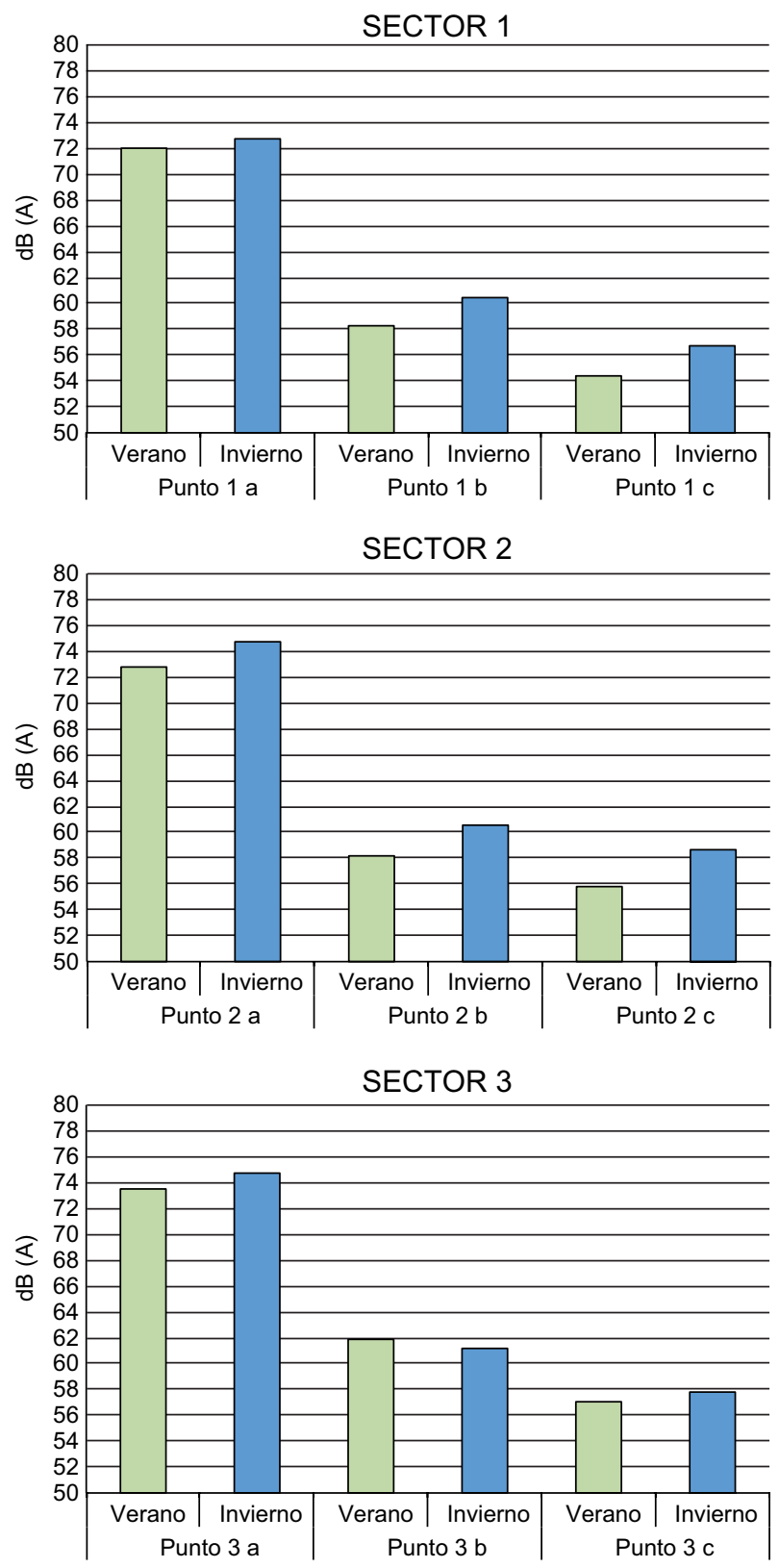

Fig. 8. Niveles medios de presión sonora para verano (VER.) e invierno (INV.)

con elevado flujo vehicular -condición de la Avenida Gobernador Videla- hace necesario considerar la función del parque O’Higgins como protección acústica, dado que el nivel de ruido registrado en la zona excede los límites recomendados por la OMS y referidos por Hurtley (2009).

Según diagnósticos previos de la ciudad de Mendoza, se cuenta con un mapa de ruidos (MuñozVargas y Gutiérrez 2007) que manifiesta el alto nivel de contaminación acústica debido principalmente
CUADRO V. APLICACIÓN DEL ANDEVA MEDIANTE InfoStat. CELDAS RESALTADAS INDICAN DIFERENCIAS SIGNIFICATIVAS

\begin{tabular}{cccc}
\hline Sector & Puntos de medición & \multicolumn{1}{c}{ F } & Probabilidad \\
\hline 1 & a & 5.138 & 0.063 \\
1 & b & 3.483 & 0.111 \\
$\mathbf{1}$ & c & $\mathbf{1 2 . 0 8 5}$ & $\mathbf{0 . 0 1 3}$ \\
$\mathbf{2}$ & $\mathbf{a}$ & $\mathbf{8 . 6 8 3}$ & $\mathbf{0 . 0 2 5}$ \\
2 & b & 5.549 & 0.056 \\
$\mathbf{2}$ & c & $\mathbf{7 . 5 0 3}$ & $\mathbf{0 . 0 3 3}$ \\
3 & a & 3.777 & 0.099 \\
3 & b & 0.4136 & 0.543 \\
3 & c & 2.257 & 0.183 \\
\hline
\end{tabular}

$\mathrm{F}=$ coeficiente de Fisher

al flujo vehicular. El diagnóstico muestra valores elevados en el micro y macrocentro de la ciudad, registrando en las distintas franjas horarias (matutina, vespertina y nocturna) valores promedio de 60 a $70 \mathrm{~dB}(\mathrm{~A})$, los cuales superan el límite propuesto por la OMS.

Según la hipótesis de trabajo, la presencia del parque O'Higgins dentro de la trama consolidada de la ciudad y colindante con una arteria de alto flujo vehicular, puede comportarse como una barrera eficaz que mitiga la contaminación sonora del entorno de ese espacio verde. El mayor efecto de amortiguación de ruidos se evidencia significativamente en el sector 2 dado que presenta un mayor volumen de vegetación.

En este sentido, el diagnóstico de la contaminación acústica, la evaluación del comportamiento de los espacios verdes como pantallas antirruido y las estrategias de mitigación de la contaminación sonora, contribuyen positivamente a la sustentabilidad ambiental del hábitat construido y en particular de una ciudad como Mendoza, en activo proceso de crecimiento y densificación. En el contexto analizado la incidencia de la vegetación del parque O’Higgins para mitigar o enmascarar la contaminación sonora resultó acotada según los valores de nivel de presión sonora obtenidos. Por tanto y en función de aumentar su potencial como barrera natural antirruido, es recomendable al momento de elaborar un plan de rediseño y reforestación, una apropiada selección de especies. La misma debería contemplar un mayor número de especies perennifolias de bajo requerimiento hídrico adaptables a la zona árida donde vegetarán, a fin de asegurar su crecimiento, aumentar la biomasa y lograr una adecuada combinación de árboles, arbustos y magnitudes forestales, que conserven el follaje en invierno y actúen como barreras eficientes a lo largo 
CUADRO VI. COMPARACIÓN DE NIVELES DE PRESIÓN SONORA MEDIDOS in situ Y CALCULADOS EN GABINETE

\begin{tabular}{|c|c|c|c|c|c|c|c|c|c|}
\hline \multicolumn{10}{|c|}{ Nivel de presión sonora promedio $[\mathrm{dB}(\mathrm{A})]$} \\
\hline \multirow{2}{*}{$\begin{array}{l}\text { Sector } \\
\text { Puntos de medición }\end{array}$} & \multicolumn{3}{|c|}{1} & \multicolumn{3}{|c|}{2} & \multicolumn{3}{|c|}{3} \\
\hline & $1 \mathrm{a}$ & $1 b$ & $1 \mathrm{c}$ & $2 \mathrm{a}$ & $2 b$ & $2 \mathrm{c}$ & $3 a$ & $3 b$ & $3 c$ \\
\hline \multicolumn{10}{|c|}{ VERANO } \\
\hline $\mathrm{R}:$ distancia (m) & 7.5 & 75.0 & 164.0 & 7.5 & 64.0 & 136.0 & 7.5 & 51.0 & 111.0 \\
\hline Leq medido $[\mathrm{dB}(\mathrm{A})]$ & 72.0 & 58.3 & 54.4 & 72.8 & 58.2 & 55.8 & 73.5 & 61.9 & 57.1 \\
\hline $\mathrm{L}_{\text {eq }}$ calculado $[\mathrm{dB}(\mathrm{A}]$ & 72.0 & 57.2 & 52.9 & 72.8 & 58.8 & 54.8 & 73.5 & 60.8 & 56.6 \\
\hline $\mathrm{A}_{\text {tot }}[\mathrm{dB}(\mathrm{A})]$ & & 14.8 & 19.1 & & 14.0 & 18.0 & & 12.7 & 16.9 \\
\hline \multicolumn{10}{|c|}{ INVIERNO } \\
\hline R: distancia (m) & 7.5 & 75.0 & 164.0 & 7.5 & 64.0 & 136.0 & 7.5 & 51.0 & 111.0 \\
\hline $\mathrm{L}_{\text {eq }}$ medido $[\mathrm{dB}(\mathrm{A})]$ & 72.7 & 60.4 & 56.7 & 74.7 & 60.5 & 58.7 & 74.7 & 61.1 & 58.0 \\
\hline $\mathrm{L}_{\mathrm{eq}}$ calculado $[\mathrm{dB}(\mathrm{A})]$ & 72.7 & 58.1 & 54.0 & 74.7 & 60.9 & 57.0 & 74.7 & 62.1 & 58.0 \\
\hline$A_{\text {tot }}[\mathrm{dB}(\mathrm{A})]$ & & 14.6 & 18.7 & & 13.8 & 17.7 & & 12.6 & 16.7 \\
\hline
\end{tabular}

$\mathrm{L}_{\mathrm{eq}}=$ nivel sonoro continuo equivalente, $\mathrm{A}_{\mathrm{tot}}=$ atenuación total debida a todos los aportes

de todo el año. A fin de conseguir una mayor eficacia del parque como barrera de control sonoro y favorecer los beneficios ambientales de este espacio verde, en concordancia con lo sugerido por Baldauf (2017) y Nowak (2014) es deseable revisar las condiciones de diseño en términos de altura, espesor, cobertura, densidad y características de las especies a incorporar. Estas consideraciones pueden ser de utilidad para urbanistas y planificadores urbanos, que además de fortalecer las características estéticas y funcionales del parque, permiten promover la mejora de la calidad ambiental del entorno para mitigar los impactos de la contaminación en general y en particular la sonora.

\section{CONCLUSIONES}

El desarrollo de mediciones de presión sonora ha ofrecido la posibilidad de calcular indicadores acústicos y diagnosticar la contaminación sonora del parque O'Higgins. Junto con el análisis del diseño del parque, la distribución de su vegetación y el conocimiento del tipo de especies existentes, se obtiene una caracterización acústica completa.

La caracterización vegetal muestra una mayor cantidad de especies caducifolias (64-84\%) y de origen exótico (95\%) cuando una mayor proporción de especies perennifolias con follaje presente a lo largo de todo el ciclo anual, lograría una mitigación uniforme del ruido durante las cuatro estaciones, incluida el invierno.
El porcentaje de árboles ( $85 \%$ ) es mayor que el de arbustos en los tres sectores evaluados, predominando los ejemplares de segunda magnitud forestal. La especie de mayor representatividad es Fraxinus excelsior (45\%), situación que indica un alto porcentaje de vegetación arbórea monoespecífica en detrimento de la biodiversidad a la que debiera tenderse en términos de sustentabilidad ambiental a escala urbana.

El análisis de la disposición y el cálculo volumétrico de las nubes de vegetación muestra que el sector 2 es el que posee el mayor volumen vegetal $\left(26394 \mathrm{~m}^{3}\right)$ y con una distribución tal que le otorga mayor eficiencia en la atenuación de ruidos.

Si bien se esperaban mayores niveles de mitigación acústica por parte de la vegetación presente al momento de las mediciones, en ambas estaciones del año y en todos los puntos evaluados los niveles sonoros decrecieron desde el punto más próximo a la fuente emisora de ruido hasta el punto cercano al receptor. Esta disminución fue más evidente en el sector 2 del parque con mayor volumen de masa vegetal. Tanto el sector 1 como el 2 presentaron los menores valores promedio de ruido en verano debido a la mayor densidad de vegetación. En invierno el sector 1 mostró más atenuación acústica justificado por el mayor porcentaje de especies perennifolias. La prueba estadística de Tukey mostró diferencias significativas en ambos sectores entre invierno y verano, en los puntos cercanos al receptor. Aplicando la Ley de las Distancias, la correlación encontrada indica 
que los valores medidos son confiables en el sentido de que no hay errores de medición o registro, como así tampoco se han medido niveles sonoros extraños al objetivo del estudio.

Los niveles sonoros fueron mayores en invierno en la mayoría de los puntos, en correspondencia con la menor biomasa y la abundancia de especies caducifolias que durante esta estación pierden el follaje. En función del total de registros sonoros para ambas estaciones (6480 registros), la mayor atenuación acústica aportada por la vegetación se verificó en verano debido a la máxima expresión vegetativa de las especies.

\section{AGRADECIMIENTOS}

Este trabajo fue desarrollado en el marco del proyecto tesis de la Maestría en Desarrollo Sustentable del Hábitat Humano de la Universidad Tecnológica Nacional, Facultad Regional Mendoza (UTN, FRM) y el Instituto de Ambiente, Hábitat y Energía (INAHE), Centro Científico Tecnológico (CONICET) MENDOZA.

Los autores agradecen a los integrantes del Laboratorio de Acústica de la UTN-FRM por la asistencia y colaboración en las mediciones de ruido realizadas in situ. También a la Agencia Nacional de Promoción Científica y Tecnológica (ANPCyT) por la financiación a través del proyecto de investigación PICT0611-2011 Préstamo BID MACANTON. Se agradece también a Alicia Bucasta, profesional de apoyo a la investigación científica del Instituto de Ambiente, Hábitat y Energía (INAHE), por la corrección de estilo y edición final del manuscrito.

\section{REFERENCIAS}

Accolti E. y Miyara F. (2010). Tools for studying noise effects based on spectral and temporal content. Memorias. XXXIX Congreso Internacional de Ingeniería de Control de Ruido. Lisboa, Portugal. 13 al 16 de junio, 2010. CD ROM.

Baldauf R. (2017). Roadside vegetation design characteristics that can improve local near-road air quality. Transp. Res. D. 52 (11), 354-361.

DOI: $10.1016 /$ j.trd.2017.03.013

Brambilla G., Gallo V., Asdrubali F. y D'Alessandro F. (2013). The perceived quality of soundscape in three urban parks in Rome. J. Acoust. Soc. Am. 134, 832839. DOI: $10.1121 / 1.4807811$
Cantón M.A. y Martinez C.F. (2009). Sustentabilidad del bosque urbano en zonas áridas. Análisis y diagnóstico de la condición de las arboledas en Mendoza-Argentina. Memorias. VI Congreso IberoAmericano de Parques y Jardines Públicos. Póvoa de Lanhoso, Portugal. 24 al 26 de junio, 2009. CD-ROM.

Correa E., Martinez C., Córica L., Cantón M., Pattini A. y Lesino G. (2007). Impacto sobre la visión de cielo de las distintas densidades edilicias forestadas. Evaluación a partir de imágenes hemiesféricas. Memorias. V Latin-American Meeting on Comfort and Energy Efficiency in the Built-Up Environment. XII Brazilian Meeting on Comfort and Energy Efficiency in the Built-Up Environment. Ouro Preto, Brasil. 8 al 10 de agosto, 2007, pp 415-424.

Demaria-Castañeda I., Colorado-Aranguren D., SerranoPérez M. y Abad-Toribio L. (2014). Evaluación de la calidad acústica en los grandes parques urbanos. Memorias. XXXXV Congreso Español de Acústica. VIII Congreso Ibérico de Acústica. Murcia, España. 29 al 31 de octubre, 2014. CD-ROM.

DNRPA (2017). Estadística anual del parque activo. Dirección Nacional de los Registros de la Propiedad del Automotor [en línea]. http://www.dnrpa.gov.ar/ portal_dnrpa/boletines_estadisticos2.php 10/08/2017.

Dzhambov A.M. y Dimitrova D. (2015). Green spaces and environmental noise perception. Urban Forest. Urban Green. 14 (4), 1000-1008.

DOI: 10.1016/j.ufug.2015.09.006

Francis C. y Barber J.R. (2013). A framework for understanding noise impacts on wildlife: an urgent conservation priority. Front. Ecol. Environ. 11 (6), 305-313. DOI: $10.1890 / 120183$

Hagler G. S. W., Lin M. Y., Khlystov A., Baldauf R. W., Isakov V. y Faircloth J. (2012). Field investigation of roadside vegetative and structural barrier impact on near-road ultrafine particle concentrations under a variety of wind conditions. Sci. Total Environ. 419, 7-15.

DOI: $10.1016 /$ j.scitotenv.2011.12.002

Halim H., Abdullah R., Ali A.A.A. y Nor M.J.M. (2015). Effectiveness of existing noise barriers: comparison between vegetation, concrete hollow block, and panel concrete. Procedia Environ. Sci. 30, 217-221.

DOI: 10.1016/j.proenv.2015.10.039

Harris C. (1998). Manual de medidas acústicas y control del ruido. MacGraw-Hill. Madrid, España, 1208 pp.

Higueras E. (2006). Urbanismo bioclimático. Gustavo Gili, Barcelona, España, 241 pp.

Hurtley C. (2009). Night noise guidelines for Europe. WHO Regional Office for Europe, Copenague, Dinamarca, $162 \mathrm{pp}$ 
INDEC (2010). Censo 2010. Instituto Nacional de Estadísticas y Censos. [en línea]. https://www. indec.gov.ar/nivel 4 default.asp?id tema $1=2 \&$ id tema_2=41\&id_tema_3=135 27/03/2017.

IRAM (2016). Ruidos molestos al vecindario. Método de medición y clasificación. Instituto Argentino de Normalización y Certificación. Norma IRAM 4062, Buenos Aires, Argentina, 24 pp.

ISO (2016). N 9613-2. Acoustics-attenuation of sound during propagation outdoors. Part 2: General method of calculation. International Organization for Standardization ISO. Ginebra, Suiza. 1 de diciembre de 2016.

Martinez C.F., Córica L., Endrizzi M., Pattini A. y Cantón M.A. (2006). Effect of urban forest on daylight availability in built environments. The case of metropolitan area in Mendoza. Memorias XXIII International Conference on Passive and Low Energy Architecture. Génova, Suiza. 6 al 8 de septiembre, 2006. CD-ROM.

Muñoz-Vargas G. y Gutiérrez L. (2007). Medición de los Niveles de Emisión Sonora en la Ciudad de Mendoza. Informe a la Municipal de la Ciudad de Mendoza - Laboratorio de Acústica "Mario G. Camín". Universidad Tecnológica Nacional, Facultad Regional Mendoza (UTN-FRM). Mendoza, Argentina, 12 pp.

Nowak D.J., Hirabayashi S., Bodine A. y Greenfield E. (2014). Tree and forest effects on air quality and human health in the United States. Environ. Pollut. 193, 119-129. DOI: 10.1016/j.envpol.2014.05.028
Parlamento Europeo (2017). La contaminación atmosférica y acústica. Artículos 191 a 193 del Tratado de Funcionamiento de la Unión Europea. Parlamento Europeo [en línea]. http://www.europarl.europa.eu/ factsheets/es/sheet/75/la-contaminacion-atmosfericay-acustica 04/08/2017.

Pérez-Porto J. (2016). Contaminación sonora. Definición. [en línea]. https://definicion.de/contaminacion-sonora/ 21/01/2017.

Pigasse G. y Kragh J. (2011). Optimised noise barriers. [en línea]. http://www.vejdirektoratet.dk/DA/ viden_og_data/publikationer/Lists/Publikationer/Attachments/499/rapport\%20194_web.pdf 08/07/2017.

Recuero-López M. (1999). Ingeniería acústica. Paraninfo. Madrid, España, 696 pp.

Ruiz M.A. y Correa E.N. (2015). Adaptive model for outdoor thermal comfort assessment in an oasis city of arid climate. Build. Environ. 85, 40-51. DOI: 10.1016/j. buildenv.2014.11.018

Samara T. y Tsitsoni T. (2007). Road traffic noise reduction by vegetation in the ring road of a big city. Memorias. International Conference on Environmental Management, Engineering, Planning and Economics. Eskíatos,Grecia. 24 al 28 de junio, 2007, pp 2591-2596.

Tong Z, Baldauf R.W., Isakov V., Deshmukh P. y Zhang K.M. (2016). Roadside vegetation barrier designs to mitigate near-road air pollution impacts. Sci. Total Environ. 541, 920-927. DOI: 10.1016/j.scitotenv.2015.09.067 